
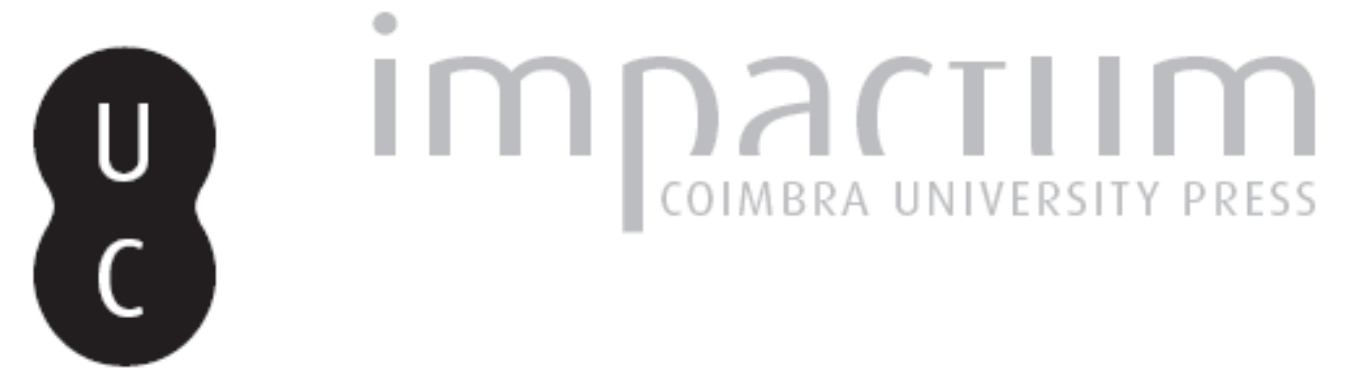

\title{
As fíbulas do Museu Municipal da Figueira da Foz
}

Autor(es): $\quad$ Ponte, Sálete da

Publicado por: Imprensa da Universidade de Coimbra

URL persistente:

URI:http://hdl.handle.net/10316.2/45707

DOI:

DOI:https://dx.doi.org/10.14195/1647-8657_21_6

Accessed : $\quad$ 26-Apr-2023 11:57:45

A navegação consulta e descarregamento dos títulos inseridos nas Bibliotecas Digitais UC Digitalis, UC Pombalina e UC Impactum, pressupõem a aceitação plena e sem reservas dos Termos e Condições de Uso destas Bibliotecas Digitais, disponíveis em https://digitalis.uc.pt/pt-pt/termos.

Conforme exposto nos referidos Termos e Condições de Uso, o descarregamento de títulos de acesso restrito requer uma licença válida de autorização devendo o utilizador aceder ao(s) documento(s) a partir de um endereço de IP da instituição detentora da supramencionada licença.

Ao utilizador é apenas permitido o descarregamento para uso pessoal, pelo que o emprego do(s) título(s) descarregado(s) para outro fim, designadamente comercial, carece de autorização do respetivo autor ou editor da obra.

Na medida em que todas as obras da UC Digitalis se encontram protegidas pelo Código do Direito de Autor e Direitos Conexos e demais legislação aplicável, toda a cópia, parcial ou total, deste documento, nos casos em que é legalmente admitida, deverá conter ou fazer-se acompanhar por este aviso.

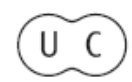


FACULDADE DE LETRAS

INSTITUTO DE ARQUEOLOGIA

\section{CONIMBRIGA}

VOLUMEXXI

UNIVERSIDADE DE COIMBRA

1982 


\section{Sálete da Ponte}

Conservadora do Museu Monográfico de Conimbriga

\section{AS FIBULAS DO MUSEU MUNICIPAL DA FIGUEIRA DA FOZ}

Conimbriga, XXI (1982), p. 151-161

SUMÁR IO: Provenientes de estações arqueológicas do Baixo Mondego e do

Algarve, o Museu da Figueira da Foz guarda um grupo de 13 fíbulas, na sua maior parte já publicadas por Santos Rocha. Tendo sido recentemente tratadas no laboratório do Museu de Conimbriga, as fíbulas justificam esta nova publicação, com melhor ilustração do que aquela que o seu descobridor pôde fazer no princípio do século.

RÉSUMÉ: Un groupe de 13 fibules trouvées dans des sites de l'àge du Fer ou romains de la basse vallée du Mondego et de l'Algarve, en partie déjà publiées par Santos Rocha, est ici repris. Le nettoyage récent des ces fibules au laboratoire du musée de Conimbriga permet aujourd'hui meilleure illustration et une étude plus poussée que celle que Santos Rocha a fait au début de ce siècle. 
(Página deixada propositadamente em branco) 


\section{AS FÍBULAS DO MUSEU MUNICIPAL DA FIGUEIRA DA FOZ}

Possui este museu $\left({ }^{x}\right) 13$ peças de bronze, provenientes do castro de Santa Olaia, freguesia de Ferreira-a-Nova, concelho da Figueira da Foz (n.os 1-3, 5-6), do castro de Tavarede, freguesia de Tavarede, concelho da Figueira da Foz (n.os 4, 7-9), da necrópole de Fonte Velha, freguesia de Bensafrim, concelho de Lagos (n.os 10-11) e da villa romana (?) da Pedrulha (Alhadas de Baixo), freguesia de Alhadas e concelho da Figueira da Foz (n. ${ }^{\text {os }}$ 12-13). Receberam todas elas tratamento adequado $\left(^{2}\right)$ no Museu Monográfico de Conimbriga. Devido ao mau estado de conservação em que se encontravam, corriam o perigo de alteração de forma, mormente os n. os 1-9; após o tratamento, alguns exemplares (n. ${ }^{\circ}$ 2-5, 7) apresentam um perfil bem mais definido do que o ilustrado pelos desenhos de Santos Rocha ( $\left.{ }^{3}\right)$.

$\mathrm{O}$ fragmento $\mathrm{n}^{\circ} 1$ resume-se ao fusilhão que, pela sua curvatura e existência de uma espira, se enquadra no grupo de

(q Estudámos já, noutros artigos, duas outras fíbulas do Museu Municipal Dr. Santos Rocha, da Figueira da Foz: uma, de tipo Aucissa com marca DYRNAGVS, achada em Fonte Velha, nas «Actas do XII Congreso Nacional de Arqueologia», Saragoça, 1973, p. 363-368; outra, sem mola, proveniente de Santa Olaia em «Conimbriga», Coimbra, XIX, 1980, p. 159-162.

${ }^{2}$ ) Procedeu-se inicialmente a uma limpeza mecânica; posteriormente foram impregnadas numa solução alcoólica de benzotriazole a $3^{\circ}{ }_{0}$ e lacadas com Incralac.

(3) Cf. António dos Santos Rocha, Memórias e Explorações Arqueológicas , vol. II. Estações pré-romanas da Idade do Ferro nas vizinhanças da Figueira, Coimbra, 1971 (= SAntos Rocha, Memórias), Est. Ill, 23; Est. IV, 24-25 (Santa Olaia); Est. XXVIII, 332-333 (castro de Tavarede).

Conimbriga, 21 (1982), 151-161 
fíbulas da $1 .^{\mathrm{a}}$ Idade do Ferro $\left(^{4}\right)$. O perfil tanto pode sugerir a fíbula de dupla mola $\left({ }^{5}\right)$ como o tipo Alcores $\left(^{6}\right)$ ou os seus protótipos itálicos $\left({ }^{7}\right)$. Julgamos, no entanto, que este fragmento terá pertencido a uma fíbula de tipo Alcores do género da de Conimbriga $\left(^{8}\right.$ ) e não a uma de dupla mola, pois a espessura da espira e a sua orientação pressupõem a existência de um fio que funcionaria de eixo. Apoiamo-nos nos modelos de Gonimbriga $\left({ }^{9}\right)$ e de Alcores de Carmona $(10 *)$.

$\mathrm{O}$ tipo Alcores difunde-se em larga escala na zona situada a sul do Tejo nos finais do séc. YIII ou inícios do VII a.C.; no nosso território, para além deste exemplar de Santa Olaia, conhecemos algumas fíbulas de Conimbriga ( $\mathrm{n}$ ) e da Horta das Pinas - Eivas (12).

(4) Cf. Emeterio Cuadrado, Precedentes y prototipos de la fibula anular hispánica, Madrid, 1963 (=CUAdrado, Precedentes), p. 19, fig. 3 e p. 27, fig. 5; Wilhelm Schüle, Die Meseta-Kulturen der Iberischen Halbinsel, Berlim, 1969 (= Schule, Die Meseta-Kulturen), p. 144, fig. 41 e p. 146, fig. 47-48.

(5) Cf. Cuadrado, Precedentes, p. 19, fig. 3; Schule, p. 144, fig. 41; Wilhelm Schule, $V$ or formt $n$ von fusszier und armbrust- Konstruktion der $H$ allstatt-D-Fibeln, «Madrider Mitteilungen», 2, 1961, Berlim, p. 55-69 (= SCHULE, Fibeln), fig. 11, n.os 1-11.

$\left({ }^{6}\right)$ Cf. Cuadrado, Precedentes, p. 27, fig. 5; Schule, Die Meseta-Kulturen, p. 146, fig. 47-48.

${ }^{7}$ Cf. Cuadrado, Precedentes, p. 24, fig. 3, i, k.

$(8)$ Cf. Adilia Moutinho Alarcào e Sálete da Ponte, Fouilles de Conimbriga, voi. VII, (Trouvailles Diverses-Conclusions Générales), Paris, 1979 (=A. Alarcào e Ponte, Fouilles de Conimbriga, VII), p. 110, Est. XXIV, 2. Este exemplar provém do nível de abandono do habitat indígena do sector termal na época claudiana.

(9) Cf. A. Alarcào e Ponte, Fouilles de Conimbriga, VII, p. 110, Est. XXIV, 2.

(10) Cf. Cuadrado, Precedentes, fig. 5, a-e; Schule, Die Meseta-Kulturen, p. 146 , fig. 47.

(") Cf. A. Alarcào e Ponte, Fouilles de Conimbriga, VII, p. 110, Est. XXIV, 2.

12 Cf. Abel Viana e António Dias de Deus, Campos de urnas do concelho de Eivas, Coimbra, 1958, p. 57, Est. XXIII, 193. Este exemplar tem de compr. total: $95 \mathrm{~mm}$. Sugere um dos modelos de Alcores de Carmona, cf. Schule, Die Meseta-Kulturen, p. 146, fig. 47 (tipo Schule 2 f).

Conimbriga, 21 (1982), 151-161 
Os n. ${ }^{\text {s }}$ 2-4 integram-se no tipo Bencarron-Schüle $4 \mathrm{~b}\left({ }^{13}\right)$, que apresentam um arco de feição laminar, um pé longo terminado num pequeno apêndice caudal, um fusilhão recto e um eixo de mola rudimentar; o fusilhão situa-se ou à direita do arco (14) ou a meio do eixo, quando este se torna independente $\left({ }^{15}\right)$ ou quando o arco apresenta uma lâmina de duas faces nervuradas (16). É o caso dos nossos exemplares; o n. ${ }^{\circ} 3$, porém, só conserva as voltas correspondentes a cada uma das faces do arco bifurcado que Santos Rocha reproduz.

Conhecemos vários exemplares em Santa Olaia, Conimbriga (17), Quintos, Bencarron (Sevilha), Sanchorreja (Ávila) e na província de León $\left({ }^{18}\right)$. Este tipo situa-se entre a 2. ${ }^{\text {a }}$ metade do séc. vu a.C. e os inícios do vi a.C. $\left({ }^{19}\right)$.

$\mathrm{O}$ n. ${ }^{\circ} 5$ aproxima-se morfologicamente do tipo Bencarron $\left(^{(20)}\right.$, conquanto apresente o arco, a mola e o fusilhão feitos de um só arame; o eixo é o único elemento independente; porém, o fusilhão ainda se situa na extremidade do eixo e à direita do arco como no modelo clássico de Bencarron.

(13) Cf. Schule, Die Meseta-Kulturen, p. 147, fig. 51; Cuadrado, Precedentes, p. 32, fig. 6.

(14) Cf. Schule, Die Meseta-Kulturen, p. 147, fig. 51; Cuadrado, Precedentes, p. 32, fig. 6, a-f; A. Alarcào e Ponte, Fouilles de Conimbriga, $V I I$, p. Ill, Est. XXIV, 4.

(15) Cf. A. Alarcào e Ponte, Fouilles de Conimbriga, VII, p. 111, Est. XXIV, 3; SÁlete DA Ponte, Fíbulas pré-romanas e romanas de Conimbriga, «Conimbriga», XII, 1973, p. 159-197 (- Ponte, Fíbulas de Conimbriga), p. 166-168, Est. II, 4.

(16) Cf. Santos Rocha, Memorias, p. 45, Est. IV, 25. O arco bifurcado desintegrou-se devido ao estado de corrosão apresentado.

${ }^{(17)}$ Cf. Ponte, Fíbulas de Conimbriga, p. 168, Est. II, 4; A. Alarcão E Ponte, Fouilles de Conimbriga, VII, p. Ili, Est. XXIV, 3-4; Schule, Fibeln, fig. 19, n.0s 1-2 (o n. ${ }^{\circ} \mathbf{1}$ desintegrou-se) ; CuAdrado, Precedentes, fig. 6 , b-c.

(18) Cf. Cuadrado, Precedentes, fig. 6; SChule, Fibeln, fig. 18, n. ${ }^{\circ} \mathbf{1}$; A. Alarcào e Ponte, Fouilles de Conimbriga, VII, p. 112.

(19) Cf. A. Alarcìo e Ponte, Fouilles de Conimbriga, VII, p. 111.

(20) Cf. SCHüle, Die Meseta-Kulturen, p. 147, fig. 51; CuAdrado, Precedentes, p. 32, fig. 6. 
Conhecemos, como paralelos para o n. ${ }^{\circ}$, dois exemplares de Conimbriga $\left({ }^{21}\right)$, os quais foram recolhidos em níveis de enchimento para a construção do forum augustano.

0 n. ${ }^{\circ} 6$ pertence ao tipo Acebuchal-Schüle $4 \mathrm{c}\left({ }^{22}\right)$, que apresenta um arco de feição laminar e nervurado, mola bilateral de corda interior ou exterior ao arco, pé longo que ao dobrar-se forma um apêndice caudal coroado num botão ou numa cabeça de animal e eixo independente; o apêndice caudal da fíbula agora estudada é semelhante ao de dois outros exemplares, um de Conimbriga e outro de Torre de Palma (23). Esta modalidade acusa, em relação ao tipo Bencarron, duas diferenças estruturais bem distintas: o eixo independente e a mola bilateral; contudo, o primeiro elemento aparece já nalguns sub-tipos Bencarron (24). O tipo Acebuchal aparece em toda a Península, e, em França, no Languedoc e na Aquitânia (2õ) ; datamo-lo dos finais do séc. vu a.C. ou dos inícios do vi a.C.

$\mathrm{O}$ n. ${ }^{\circ} 7$ corresponde ao tipo Golfo de Leão $\left({ }^{26}\right)$, que apresenta arco, mola e fusilhão feitos de um só arame; o arco é de feição filiforme ou laminar; a mola é bilateral de corda interior ou exterior ao arco; o pé é longo e termina num pequeno apêndice caudal que poderá ser ou não coroado por um botão; o eixo constitui uma peça independente.

Conhecemos no nosso território, para além do exemplar ilustrado do castro de Tavarede, outros em Conimbriga (27) e Vaia-

(21) Cf. A. Alarcão e Ponte, Fouilles de Conimbriga, VII, p. 112, Est. XXIV, 5 e 7.

(22) Cf. Seni le, Die Meseta-Kulturen, p. 147, fig. 52, 4 C; Cuadrado, Precedentes, p. 32-34, fig. 7; A. Alarcão e Ponte, Fouilles de Conimbriga, $V I I$, p. 113-114.

(23) Cf. A. Alarcão e Ponte, Fouilles de Conimbriga, VII, p. 113, Est. XXIV, 12. O exemplar de Torre de Palma (Monforte) està ainda inèdito e encontra-se depositado no M. N. A. E.; foi achado no cemitério ao pé das Ermidas (Torre de Palma).

(24) Cf. id. ibidem, p. 112, Est. XXIV, 3, 5 e 7.

(25) Cf. id., ibidem, p. 114.

(26) Cf. Cuadrado, Precedentes, p. 34, fig. 8.

(27) Cf. A. Alarcão e Ponte, Fouilles de Conimbriga, VII, p. 112, Est. XXIV, 9-10 e Est. XXV, 11; os dois primeiros foram recolhidos em níveis de enchimento; o último provém de um nível trajânico das termas. 
monte (28) ; aparece ainda no Languedoc, Catalunha, Sória e Guadalajara na 2. ${ }^{\text {a }}$ metade do séc. vi-v a.C. $\left({ }^{29}\right)$.

$\mathrm{O}$ n. ${ }^{\circ} 8$ integra-se no grupo de fíbulas anulares hispánicas, ou seja, no tipo 11 de Cuadrado $\left(^{30}\right)$; caracteriza-se por apresentar o arco, mola e fusilhão feitos de um só arame; o arco em forma de cinta ou fita é sublinhado por um sulco longitudinal; a mola é bilateral e de corda interior ao arco; o aro é de secção variável.

Esta modalidade é pouco vulgar na Península. Conhecemos, além do n. ${ }^{\circ}$, alguns exemplares de La Osera ( $\left.{ }^{31}\right)$.

Este tipo situa-se nos finais do séc. iv ou nos inícios do ui a.C. $\left({ }^{32}\right)$.

O n. ${ }^{\circ} 9$ corresponde ao grupo de fíbulas ditas de «charneira e arco triangular» - tipo 28 de Ettlinger ( $\left.{ }^{33}\right)$. O nosso exemplar apresenta, não um arco de feição triangular, mas oval com charneira muito rudimentar; por um lado, o arco sugere-nos alguns modelos de tipo Nauheim - tipo Camulodunum B (34) e, por outro, a charneira acusa influência dos primeiros modelos de charneira de arco triangular $\left({ }^{35}\right)$. Assim, entendemos que o n. ${ }^{\circ} 9$

(28) Cf. Sálete da Ponte, Fíbula de Vaiamonte (Monforte), comunicação apresentada no «3..$^{\circ}$ Colóquio Internacional de Línguas e Culturas Paleo-Hispânicas», Lisboa, 1980, n. ${ }^{\circ} 2-4$.

(29) Cf. Cuadrado, Precedentes, p. 36; A. Alarcão e Ponte, Fouilles de Conimbriga, VII, p. 112-114.

(30) Cf. Emeterio CUADRADo, La fibula anular hispánica y sus problemas, Salamanca, 1957 (=CuAdrado, Problemas), p. 18, fig. 26, 1-3.

(31) Cf. Cuadrado, Problemas, p. 40 e 58, fig. 26, 2-3.

(32) Cf. id., ibidem, p. 59.

(33) Cf. Elisabeth Ettlinger, Die Römischen Fibeln in der Schweiz, Berna, 1973 (= Etthinger, Die Fibeln in der Schweiz), p. 89-92, Est. 8, n.os 6-18; Est. 9, n.os 1-5; A. Alarcĩo e Ponte, Fouilles de Conimbriga, $V I I$, p. $118-119$.

${ }^{(34)}$ Cf. C. F. C. Hawkes e M. F. Hull, Camulodunum. First report on the excavations at Colchester 1930-1939, Oxford, 1947 (= HaWKES e HuLL, Camulodunum), p. 312; A. Alarcão e Ponte, Fouilles de Conimbriga, VII, p. 117, Est. XXVI, 43. Este exemplar apareceu numa camada trajânica das termas associado a material datado dos finais do séc. i a.C. e $1 .^{\circ}$ metade do i d.C.

(35) Cf. ettuinger, Die Fibeln in der Schweiz, Est. 8, n. ${ }^{\text {os }}$ 6-9; Miche L FEUG È RE, Les fibules gallo-romaines du Musée Denon à Châlon-sur-Saône 
não deverá situar-se antes dos finais do séc. i a.C. - inícios do i d.C., dado que a categoria em que se insere atinge o seu pleno desenvolvimento na $2 .{ }^{\text {a }}$ metade do séc. i d.C. $\left({ }^{36}\right)$.

Os n. os 10-12 correspondem ao grupo de fíbulas de tipo Aucissa(37), ou seja, ao tipo Camulodunum 17 ( $\left.{ }^{38}\right)$, que apresenta um arco semicircular, pé curto e coroado por um botão de recorte variável, descanso de feição triangular, fusilhão recto, cabeça em charneira e eixo com botões terminais simples ou decorativos.

Os n.os 10-11 pertencem ao tipo 17 B de Camulodunum, que apresenta arco semicircular, sublinhado a meio por uma moldura longitudinal relevada, pé curto biselado, placa e carteia de feição rectangular e decoradas com motivos geométricos e botões decorativos no pé e nos extremos do eixo. Esta modalidade surge com abundância em diversos locais romanos, nomeadamente em Vindonissa $\left({ }^{39}\right)$, Richborough $\left({ }^{40}\right)$, Saalburg $\left({ }^{41}\right)$ e Conimbriga $\left({ }^{42}\right)$, desde Tibério aos Flávios; conhecemos, ainda no nosso país, mais alguns paralelos no castro de S. Salvador - Santarém $\left({ }^{43}\right)$,

(Mémoires de la Société d'Histoire et d'Archéologie de Châlon-sur-Saône, vol. XLVIII), Châlon-sur-Saône, 1977, p. 77-158 (= Feugère, Musée Denon), p. 116 , fig. 11 , n. $^{\circ} 9$ e Est. 9 , n. $^{\circ} 50$ (Alésia).

,...(36) Cf. Sheppard Frere, Verulamium. Excavations, vol. I, Oxonia, 1972 (Frere, Verulamium), p. 13 e 116, fig*. 30, n. ${ }^{\circ} 18$. O autor data-o de.43-60 d.C. ; A. Alarcão e Ponte, Fouilles de Conimbriga, VII, p. 118-119, Est. XXVII, 47, 50; o primeiro foi achado num nível trajânico das termas; o segundo, numa camada pré-flaviana da zona do templo.

${ }^{(37)}$ Cf. A. Alarcão e Ponte, Fouilles de Conimbriga, VII, p. 119.

(38) Cf. Hawkes e Hull, Camulodunum, p. 322.

(39) Cf. Eтtuinge R, Die Fibeln in der Schweiz, p. 93-94, Est. 9, n.os 6-8.

(40) Cf. BARRY CUNLIFFE, $F$ ift th report on the excavations of the Roman fort at Richborough, Kent, Oxónia, 1968, p. 77-93 (p. 84, Est. 30, n. ${ }^{\circ} 42$ ).

(41) Cf. Hans-Günther Simon, Das klein Kastell Degerfeld in Rutzbach, Kr. Friedberg (Hessen): Datierung und Funde, «Saalburg-Jahrbuch», Berlim, 25, 1968, p. 5-64 (p. 29, fig. 9, n. ${ }^{\circ}$ 1).

$\left({ }^{42}\right)$ Cf. A. Alarcĩo e Ponte, Fouilles de Conimbriga, VII, p. 119, Est. XXVII, 56-58.

(43) Cf. Sálete da Ponte, Uma colecção de fíbulas do distrito de Santarém, artigo a publicar no «Boletim Distrital de Lisboa», Lisboa, 1982 (=ロ Ponte, Distrito de Santarém), $n .^{\circ} 11$.

Conimbriga, 21 (1982), 151-161 
S. Miguel de Odrinhas — Sintra $\left({ }^{44}\right)$ e Miróbriga $\left({ }^{45}\right)$ mas desprovidos de contexto estratigráfico.

$\mathrm{O}$ n. ${ }^{\circ} 12$ integra-se no tipo $17 \mathrm{C}$ de Camulodunum (46), porque apresenta um arco espalmado, de secção semicircular ou rectangular; a placa e a carteia são mais pequenas e mais sóbrias na decoração; o pé é curto; este e o eixo terminam em botões bastante simplos. Esta modalidade ocorre com frequência na Alemanha $\left({ }^{47}\right)$, Inglaterra $\left({ }^{48}\right)$ e em França $\left({ }^{49}\right)$ nos meados do séc. i d.C.; os exemplares de Conimbriga $\left({ }^{50}\right)$ fixam este modelo entre os períodos claudiano (õl) e flaviano-trajânico ( $\left.{ }^{52}\right)$; reconhecemo-la, também, em Muge $\left({ }^{\tilde{}}{ }^{3}\right)$ mas sem qualquer dado estratigráfico.

$\mathrm{O}$ n. ${ }^{\circ} 13$ corresponde ao tipo Fowler $\mathrm{Bl}\left({ }^{54}\right)$, ou seja, ao grupo de fibulas anulares romanas que apresentam as extremidades do aro em forma de molduras anelares coroadas ou não de botões

(44) Cf. Sálete da Ponte, Algumas fibulas dos concelhos de Sintra, Cascais, Amadora e Alenquer, artigo a publicar no «Boletim Cultural de Sintra», n. ${ }^{\circ} 10$.

(45) Cf. Sálete da Ponte, As fíbulas de Miróbriga, «Setúbal Arqueológica», Setúbal, 1982, (= Pont E, Miróbriga), n. ${ }^{\circ} 14$.

(46) Cf. Hawkes e Hull, Camulodnum, p. 322.

$(47)$ Cf. Günther Ulbert, Die römischen Donau-Kastelle Aislingen und

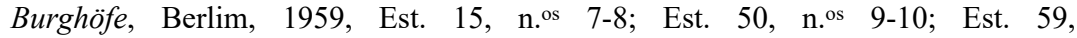
n. ${ }^{\circ} 11$ a 14; Günther Ulbert, Das fruhrömische Kastell Rheingönheim. Die Funde aus den Jahren 1912 und 1913, Berlim, 1969, Est. 22-23, n. ${ }^{\text {os }}$ 1-10; Werner Kramer, Cambodunumforschungen, 1953-1, Kallmunz, Est. 15, n. ${ }^{\text {os }} 1$ a 5 .

(48) Cf. Hawnes e Hull, Camulodunum, p. 323-324; J. W. Brails Ford, $H$ od Hill I. Antiquities from Hod Hill in the Durden Collection, Uondres, 1962, fig. 8, n.os C46-C52.

$\left({ }^{49}\right)$ Cf. U. LE RAT. Les fibules gallo-romaines de Besançon, Paris, 1956, Est. 7, n.os 140-150.

(50) Cf. A. Alarcìo e Ponte, Fouilles de Conimbriga, VII, p. 120, Est. XXVIII, 59-66.

(51) Cf. id., ibidem, p. 120, Est. XXVIII, 62 (nível claudiano da ínsula a norte das termas).

(52) Cf. id., ibidem, p. 120, Est. XXVIII, 64 (nível flaviano do forum), 61,63 e 65 (nível trajánico).

(53) Cf. Ponte, Distrito de Santarém, n. ${ }^{\circ} 13$.

$\left({ }^{\circ} 4\right)$ Cf. E. Fowler, The origins and developments of the penáñnular brooch in Europe, «Proceedings of the Prehistoric Society»,' XXVI, 1960, p. 149-177 (p. 151). 
cónicos. Esta modalidade ocorre em larga escala no mundo romano, desde o séc. i d.C. à $1{ }^{a}$ metade do $\mathrm{m}$ d.C. ( ${ }^{55}$ ); alguns dos exemplares de Conimbriga ${ }^{(56)}$ foram achados em camadas flavianas do forum e em níveis trajañicos para a reconstrução das termas; conhecemos mais exemplares em Alcácer do $\mathrm{Sal}\left({ }^{57}\right)$, Miróbriga ${ }^{(58)}$, Vaiamonte $\left({ }^{59}\right)$, Muge $\left({ }^{60}\right)$ e Vila Cardílio — Torres Novas $\left({ }^{61}\right)$, mas desprovidos de quaisquer referências estratigráficas.

\section{CATÁLOGO}

1. Fíbula de tipo Alcores (tipo Schüle 2f). que conserva o fusilhão em L e uma Inv. n. ${ }^{\circ}$ 7935. Fragmento volta da mola rudimentar. Compr. fusilhão: $72 \mathrm{~mm}$. (cf. Santos Rocha, Memórias, p. 45, Est. V, 33 - Santa Olaia. O autor considerou-o um alfinete de cabelo do tipo que se encontraria associado a peças da Idade do Bronze em França, Alemanha, Boémia e na estação pré-micénica de Hissarlik).

2. Fíbula de tipo Bencarron (tipo Shüle 4b). Inv. n. ${ }^{\circ} 2932$. O arco é laminar e de secção semicircular; do eixo resta um dos extremos em forma de laço; o pé é longo e estreito; do descanso resta apenas parte da placa de feição triangular. Compr. total: $68 \mathrm{~mm}$; alt. $30 \mathrm{~mm}$ (cf. Santos Rocha, Memórias, p. 45, Est. IV, n. ${ }^{\circ} 24$ ).

3. Id. Inv. n. ${ }^{\circ}$ 5994. Fragmento que conserva o eixo, o enrolamento do fio do arco bifurcado e parte do fusilhão. Compr. eixo: $31 \mathrm{~mm}$ (cf. Santos Rocha, Memórias, p. 45, Est. IV, n..$^{\circ} 25$ ).

4. Id. Inv. n. ${ }^{\circ}$ 1812. Falta parte do pé e do descanso. O eixo é independente; o fusilhão forma a mola rudimentar e corda interior ao arco; este é de secção semicircular. Compr.: $36 \mathrm{~mm}$; alt. $21 \mathrm{~mm}$. (cf. Santos Rocha, Memórias, Est. Ill, n. ${ }^{\circ} 23$ ).

5. Id. Variante tipo Bencarron. Inv. n. ${ }^{\circ}$ 3477. O eixo é independente; o fusilhão, na ponta direita do eixo, forma, da direita para a esquerda,

(55) Cf. A. Alarcĩo e Ponte, Fouilles de Conimbriga, VII, p. 120.

(56) Cf. $i d$. ., ibdem, p. 120.

${ }^{(57)}$ Cf. Sálete da Ponte, Fíbulas de Alcácer do Sal, comunicação apresentada no IV Congresso Nacional de Arqueologia, Faro, 1980, n.os 30-31.

(58) Cf. Ponte, Miróbriga, n.os 16-19.

$\left({ }^{(09}\right)$ Cf. Ponte, Vaiamonte, n. ${ }^{\text {os }} 81-93$.

${ }^{(60)}$ Cf. Ponte, Distrito de Santarém, n. 14.

(61) Cf. id., ibidem, n. ${ }^{\circ} 15$. 
a mola e o arco. O arco é laminar e de secção semicircular. Compr. total: $58 \mathrm{~mm}$; alt.: $28 \mathrm{~mm}$. (cf. Santos Rocha, Memorias, p. 114, Est. XXVIII, n. $\left.{ }^{\circ} 333\right)$.

6. Fibula de tipo Acebuchal (tipo Shüle 4C). O arco é laminar e sublinhado longitudinalmente por 3 molduras muito gastas; o pé longo e estreito ao dobrar-se forma um apêndice caudal em forma de cabeça de animal; o descanso é de feição triangular; da mola bilateral restam apenas 3 voltas. Compr.: $81 \mathrm{~mm}$; alt.: $25 \mathrm{~mm}$ (cf. Santos Rocha, Memórias, p. 45-46, Est. IV, n. ${ }^{\circ}$ 28; Guillermo Schüle, Las mas antiguas fibulas con pie alto y ballesta, Madrid, 1961, fig. 19, n. ${ }^{\circ}$; Cuadrado, Precedentes, fig. 7, h).

7. Fíbula de tipo Golfo de Leão. Inv. n. ${ }^{\circ} 2261$ B. Peça completa. O arco e secção são semicirculares; a mola é bilateral, de corda interior ao arco e consta de 4 voltas; o pé é estreito e longo; o descanso é de feição triangular. Compr.; $63 \mathrm{~mm}$; alt.: $20 \mathrm{~mm}$ (cf. SAntos Rocha, Memorias, p. 114, Est. XXVIII, 332).

8. Fíbula anular hispânica de tipo Cuadrado 11. Inv. n. ${ }^{\circ}$ 5254. O arco é em forma de fita ou cinta, o aro, interrompido, é de secção facetada; a mola é bilateral, de corda interior ao arco e consta de 2 voltas. Diâm. aro: $45 \mathrm{~mm}$; Compr. arco: $45 \mathrm{~mm}$; alt. arco: $25 \mathrm{~mm}$ (cf. SAntos Rосна, Memorias, p. 113-114, Est. XXIX, 343. Este autor observa que foram encontrados exemplares idênticos na necrópole íbero-púnica da Cruz del Negro e em Conimbriga; este último desaparecido).

9. Fíbula de tipo «Charneira e arco triangular» (tipo Ettlinger 28). Inv. n. ${ }^{\circ}$ 8128. O arco é de feição oval e secção semicircular; o funcionamento da cabeça é em charneira. Resta parte do fusilhão, que é independente. Compr. total: $40 \mathrm{~mm}$; alt.: $11 \mathrm{~mm}$ (cf. Santos Rocha, Memórias, p. 45-46, Est. IV, 29).

10. Fíbula de tipo Camulodunum 17 B (Aucissa). Inv. n. ${ }^{\circ}$ 4392. Falta-lhe parte do fusilhão. $\mathrm{O}$ arco é semicircular e sublinhado por urna moldura longitudinal relevada. Desenha um encordoado; o pé é curto e termina num botão cónico; a carteia e placa são decoradas, respectivamente, por um encordoado e duas finas molduras paralelas; o eixo é de ferro. Compr. total: $56 \mathrm{~mm}$; alt.: $30 \mathrm{~mm}$.

11. Id. Inv. n. ${ }^{\circ}$ 4394. Semelhante à anterior. Compr. total: $54 \mathrm{~mm}$; alt. $32 \mathrm{~mm}$.

12. Fibula de tipo Camulodunum $17 \mathrm{C}$ (Aucissa). Inv. n. ${ }^{\circ}$ 5760. Fragmento que conserva o arco, charneira, eixo e arranque do fusilhão. $\mathrm{O}$ arco laminar e de secção semicircular é decorado por 2 estreitas faixas em forma de espinha. Compr. total: $35 \mathrm{~mm}$.

13. Fíbula de tipo Fowler B 1 (anular romana). Inv. n. ${ }^{\circ} 6988 . \mathrm{O}$ arco e secção são circulares, os seus extremos terminam em botões bicónicos. Diâm. aro: $40 \mathrm{~mm}$. 

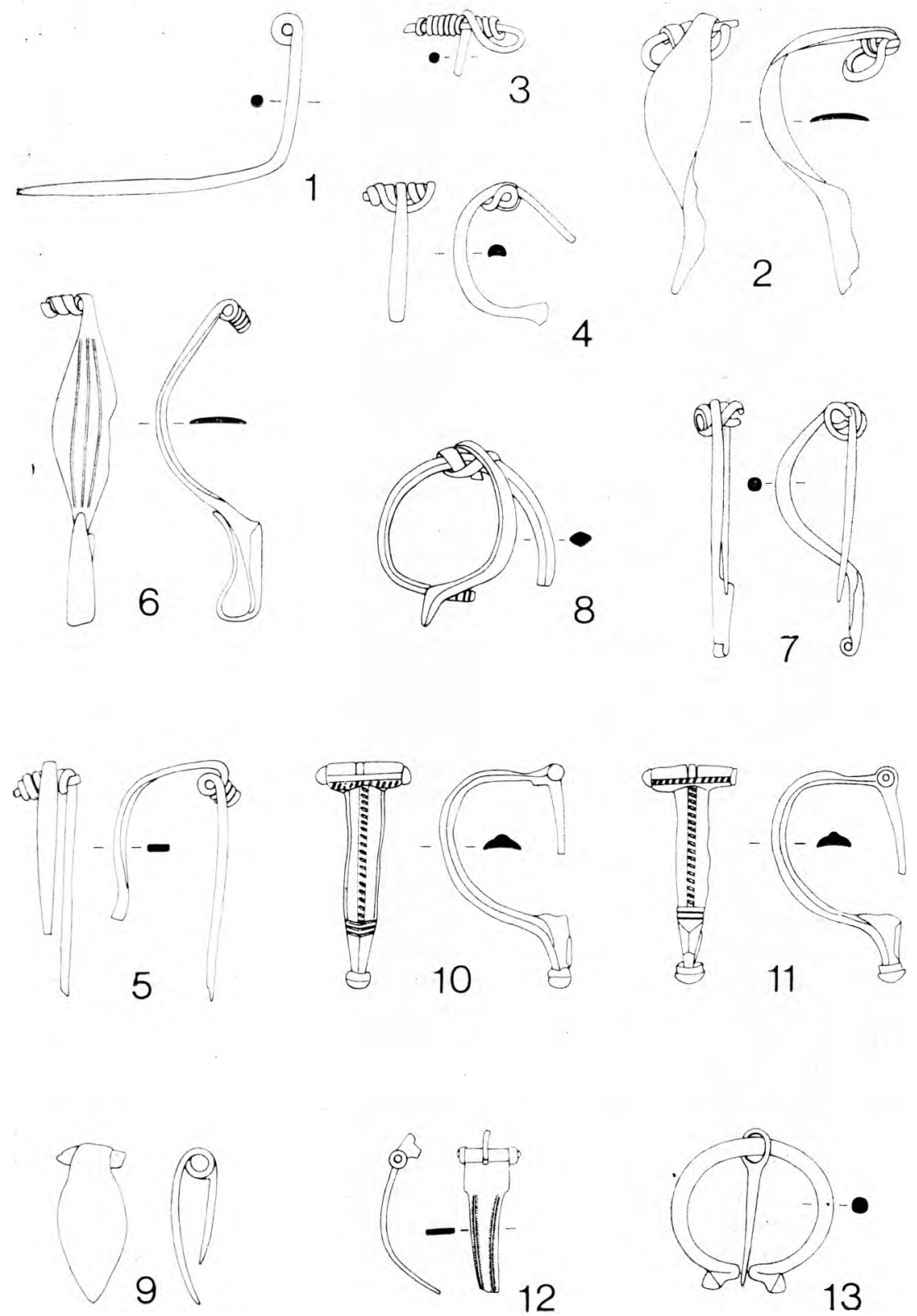